\title{
A Research of Effect of Three Sweet Potato Varieties and Addition on Resistant Starch Content and Physical Characteristics of Steamed Rice Bowl Cake
}

\author{
ChinFu Chou*, Mingchang Li \\ Department of Food Science and Nutrition, Meiho University, Pingtung 91202, Taiwan \\ *Corresponding author: x00011064@meiho.edu.tw
}

Received August 03, 2018; Revised September 10, 2018; Accepted September 17, 2018

\begin{abstract}
This research aimed to evaluate the effect of different varieties and proportion of sweet potatoes on the resistant starch content (RSC) and physical characteristics of steamed rice bowl cake. Accordingly, the research further evaluated the optimal conditions for the production of steamed rice bowl cake with high RSC. According to the research results, RSC $(10.31-12.01 \%)$ was significantly increased $(p<0.05)$ along with increasing the sweet potato proportion, where Taichung Sen 17 (TCS 17) had the lowest RSC (10.00\%). Tainung No. 66 (TN 66) with different proportions produced higher RSC $(10.60,11.18$ and 12.01\%), and was similar to the results of Tainung No. 57 (TN 57) (10.31, 10.70 and 11.16\%) and Tainung No. 73 (TN 73) (10.50, 11.17 and 11.87\%). Furthermore, significant differences $(p<0.05)$ were found in some experiment variables of texture profile analysis. Results indicated that the proportion of sweet potatoes was positively related to hardness, cohesiveness, adhesiveness, brittleness, springiness, and chewiness of steamed rice bowl cake, but $30 \%$ proportion of TN 57 was no significant differences. Besides, color analysis results of steamed rice bowl cake with different varieties and proportion of sweet potatoes were significantly different $(p<0.05)$. The TCS 17 was significantly lighter $\left(\mathrm{L}^{*}=67.99\right)$ than TN 57 $\left(\mathrm{L}^{*}=61.97,59.53\right.$ and 57.17), TN $66\left(\mathrm{~L}^{*}=51.25,49.58\right.$ and 47.41$)$ and TN $73\left(\mathrm{~L}^{*}=36.89,31.33\right.$ and 25.97$)$ with different proportion. Significant higher $(p<0.05) \mathrm{a}^{*}$ and $\mathrm{b}^{*}$ values were observed in steamed rice bowl cake of TN $66\left(\mathrm{a}^{*}=1.01,2.87\right.$ and 4.67), TN $73\left(\mathrm{a}^{*}=9.79,13.33\right.$ and 16.99) and TN $57\left(\mathrm{~b}^{*}=7.91,11.96\right.$ and 16.09), TN 66 $\left(b^{*}=22.78,30.38\right.$ and 38.11$)$, respectively.
\end{abstract}

Keywords: Taichung Sen 17, rice, sweet potato varieties, steamed rice bowl cake, resistant starch

Cite This Article: Chin Fu Chou, and Ming chang Li, "A Research of Effect of Three Sweet Potato Varieties and Addition on Resistant Starch Content and Physical Characteristics of Steamed Rice Bowl Cake." Journal of Food and Nutrition Research, vol. 6, no. 9 (2018): 551-556. doi: 10.12691/jfnr-6-9-2.

\section{Introduction}

Rice is a major crop, and it plays an important role in people's diets. About $50 \%$ of the world's population live on a diet of rice as their caloric source [1]. Furthermore, starch is the major component of rice [2], and its functional and structural properties are important.

Starch is a primary energy source in our daily diet. Starch consists different two D-glucan polymers, one is amylose, which is a primarily linear structure, and the other is amylopectin, which is a branched structure [3]. Amylose content of rice is a major factor influencing the texture, functional and physicochemical properties for rice-made food, and can be related to its rheological and swelling properties [2]. Indica rice is usually containing higher amylose content when comparing with Japonica rice, which is easy to retrograde, and further form resistant starch III (RS III, retrograded starch) [1].

Resistant Starch (RS) is defined as the sum of starch and products of starch degradation not absorbed in the small intestine of healthy individuals $[4,5,6]$. Higher RS in food can reduce the blood glucose level after a meal, which is useful in diabetes and obesity controlling $[7,8]$. Especially, RS III is particularly interesting since its functional and thermal stable properties during food processing [3].

Taichung Sen 17 (TCS 17) is the variety of rice that is with the highest amylose content. TCS 17 is only planted in Taiwan, and it benefits the RS III producing [9]. Besides, RS III formation is associated with retrograded amylose [3].The texture of rice-made food is known to easily become hard, which makes the taste worse over the time. This is because of the retrogradation resulted in RS III increasing through recrystallization of amylose. Therefore, TCS 17 has been lost the popularity since the taste and texture is not fine.

Steamed rice bowl cake is one of the traditional dishes in Taiwan, and the texture of steamed rice bowl cake is soft and stretchy. Traditionally, Indica rice has been used for making steamed rice bowl cake because it can provide a favorable texture and appearance. However, instead of Indica rice, other starch crops such as sweet potatoes have never been utilized for making steamed rice bowl cake. In 
other words, to some extent, sweet potatoes are becoming an alternative of rice.

Sweet potato (Ipomoea batatas L.) is a major food crop and is ranked after rice and maize in many developing countries [10]. The sweet potato is relatively easy to grow and with high productivity. Particularly, the high starch content [11] in which amylose content is $8.5-38 \%$ depending on the variety. The sweet potato is also rich in carbohydrate, dietary fibers, and potassium, low in fat and is an important source of the $\beta$-carotene. The sweet potato is becoming increasingly popular for various products production such as chips, drinks (wine, liquor), sugar production, flour, pasta, alcohol, etc. That is to say, the sweet potato is becoming widely accepted in the daily diet.

Steamed rice bowl cake is the one of Taiwanese traditional rice-made food, but as the impact of instant food, the consumption of rice is decreasing gradually. Therefore, promoting Taiwanese traditional rice-made food is becoming an important task. As a matter of fact, the sweet potato has been used as a food crop when the amount of rice is insufficient. The sweet potato can be planted at different periods of the year, and it is consumed as boiled roots. Moreover, the sweet potato is not only cheaper but also can be processed into different products with higher quality and longer shelf life. Different varieties of sweet potatoes differ in many of their characteristics, ranging from the physicochemical and texture properties. However, nowadays, the sweet potato has so far less utilized. Besides, research regarding the combination of both sweet potato and rice for the development of Taiwanese rice-made food is so far limited.

Overall, in order to improve the quality and functional demands of steamed rice bowl cake and to broaden the utility of rice, the objectives of this study were to investigate the effect of different varieties (ie., Tainung No. 57, Tainung No. 66 and Tainung No. 73) and proportion $(0,10,20,30 \%)$ of sweet potatoes on the RSC, texture, and color properties of steamed rice bowl cake, and finally to evaluate the optimal conditions for the production of steamed rice bowl cake with high RSC.

\section{Materials and Methods}

\subsection{Materials}

Indica rice, Taichung Sen 17 (TCS 17 grown in Taiwan) had been harvested in 2017. The total starch and amylose content of TCS 17 was analyzed by the method described by Chou et al. [1]. The total starch and amylose content of TCS 17 had been determined as 77.99 and $28.66 \%$, respectively.

Three varieties of sweet potatoes harvested in Taiwan namely yellow flesh color (Tainung No. 57; TN 57), red flesh color (Tainung No. 66; TN 66) and purple flesh color (Tainung No. 73; TN 73) were purchased from a local market. The freshly harvested material of rice and sweet potatoes were collected and stored at $7^{\circ} \mathrm{C}$ for further processing within a week. All used chemicals and reagents were in analytical grade.

\subsection{Production of Mashed Sweet Potato}

First, three varieties of sweet potatoes (TN 57, TN 66 and $\mathrm{TN} 73$ ) were allowed $2 \mathrm{~h}$ to equilibrate at room temperature. Second, these sweet potatoes were manually cleaned by hand followed with clean water to remove soils. Third, the cleaned sweet potatoes were cut into $1 \mathrm{~cm}^{3}$ volume and steamed by a steamer (Model No KS-980, Quickly Food Machinery Co., Ltd., Taoyuan, Taiwan) for $30 \mathrm{~min}$. The mashed sweet potatoes were then allowed $2 \mathrm{~h}$ to equilibrate at the room temperature and used for further processes.

\subsection{Steamed Rice Bowl Cake Preparation}

First, the rice and mashed sweet potato was then allowed $2 \mathrm{~h}$ to equilibrate at the room temperature before the preparation. Second, TCS 17 were soaked (100 g rice kernel in $350 \mathrm{~mL}$ distilled water) for $30 \mathrm{~min}$. Each group of rice and mashed sweet potato was weighed according to the ratio formula (Table 1) and steamed by a steamer (Model No KS-980, Quickly Food Machinery Co., Ltd., Taoyuan, Taiwan) for $40 \mathrm{~min}$.

Table 1. Formulas of Each Group.

\begin{tabular}{ccccc}
\hline & \multicolumn{4}{c}{ Proportion of recipe } \\
\cline { 2 - 5 } Control & TSC17 & TN 57 & TN 66 & TN 73 \\
1 & 100 & 0 & 0 & 0 \\
2 & 90 & 10 & 0 & 0 \\
3 & 80 & 20 & 0 & 0 \\
4 & 70 & 30 & 0 & 0 \\
5 & 90 & 0 & 10 & 0 \\
6 & 80 & 0 & 20 & 0 \\
7 & 70 & 0 & 30 & 0 \\
8 & 90 & 0 & 0 & 10 \\
9 & 80 & 0 & 0 & 20 \\
\hline
\end{tabular}

TN 57=Tainung No.57; TN 66=Tainung No. 66; TN 73=Tainung No. 73; TCS $17=$ Taichung Sen 17 .

\subsection{Resistant Starch Content (RSC) Analysis}

A method previously described by Chou et al. [1] for the RSC analysis was used. $0.4 \mathrm{~g}$ sample powders (dry basis) were weighed in a centrifuge tube, $20 \mathrm{~mL} \mathrm{pH} 6.0$ phosphate buffer $(55.6 \mathrm{mM})$ and $0.16 \mathrm{~g} \alpha$-amylase (Sigma A-3176, Steinheim, Germany) were added and incubated at $37^{\circ} \mathrm{C}$ for $16 \mathrm{~h}$. The sample was adjusted to $\mathrm{pH} 4.5 \mathrm{using}$ phosphoric acid solution $(2 \mathrm{~mL} / 100 \mathrm{~mL}), 0.4 \mathrm{~mL}$ amyloglucosidase (Sigma A-7095, Steinheim, Germany) was added and incubated at $60^{\circ} \mathrm{C}$ for $30 \mathrm{~min}$. After incubation, the sample was centrifuged at $4000 \times \mathrm{g}$ for 15 min by a high-speed micro centrifuge (CF15R, Hitachi, Koki, Ltd., Tokyo, Japan), the residue was resuspended in $20 \mathrm{~mL}$ pH 7.5 phosphate buffer $(0.08 \mathrm{M}), 0.4 \mathrm{~mL}$ protease (Sigma P-2143, Steinheim, Germany) was added and incubated at $42^{\circ} \mathrm{C}$ for $4 \mathrm{~h}$. Finally, the sample was centrifuged at $6000 \times \mathrm{g}$ for $15 \mathrm{~min}$, dried to constant weight at $60^{\circ} \mathrm{C}$ by a constant-temperature oven and weighed for the RS weight. The analysis was carried out in triplicate.

The RSC was calculated by the following equation:

RSC (\%, dry basis)

$=($ Resistant starch weight $/$ Sample weight $) \times 100 \%$. 


\subsection{Texture Profile Analysis (TPA)}

The textural properties of the steamed rice bowl cake were analyzed using the EZ Test-500N texture analyzer (TAXTZ-5, Shimadzu Co., Kyoto, Japan) attached to a cylindrical plunger $(10 \mathrm{~mm}$ diameter, depression speed $=$ $30 \mathrm{~mm} / \mathrm{min}$ ) and a $500 \mathrm{~N}$ load cell, by performing texture profile analysis (TPA). The freshly prepared samples were prepared by cutting the steamed rice bowl cake to cube shaped samples $(2 \mathrm{~cm}$ length $\times 2 \mathrm{~cm}$ width $\times 2 \mathrm{~cm}$ height $)$. The samples were compressed twice to $50 \%$ of the original height, texture profile analyses were determined by two compression cycles. Texture profile parameters measured include hardness, cohesiveness, adhesiveness, gumminess, brittleness, springiness and chewiness. The analysis was performed with triplicates.

\subsection{Color Determination}

Color of steamed rice bowl cake were measured using Hunter Lab Color Measuring System (Color Quest XE, Hunter Associates Laboratory, Reston, USA). The analysis was performed with triplicate.

\subsection{Statistical Analysis}

The data obtained were first calculated using Microsoft Office Excel 2010 (Microsoft Corporation, Redmond, WA). Analysis of variance (ANOVA) for the effect of varieties (TN 57, TN 66 and TN 73) and proportion $(0,10$, 20 and $30 \%$ ) on the resistant starch content and physical characteristics of steamed rice bowl cake was accomplished using the Statistical Analysis System (SAS, USA). The differences among mean values were processed by Duncan's Multiple Range Test, and significance was defined at $p<0.05$.

\section{Results and Discussion}

\subsection{Resistant Starch Content (RSC) of Steamed Rice Bowl Cake}

Table 2 shows the effects of different varieties of sweet potatoes (TN 57, TN 66 and TN 73) and proportion (10, 20 and $30 \%$ ) on the RSC of steamed rice bowl cake. The measured RSC of steamed rice bowl cake ranged between 10.00 and $12.01 \%$, which agreed with previously reported values of $8.44-12.94 \%$ [1]. This may be explained that the starch relapses to a structure during gelatinization that could be highly resistant to amylase hydrolysis which is referred to as RS [12]. Processing and storage conditions may influence the gelatinization and retrogradation processes, affecting the RS formation [13].

The temperature of steaming method is about $100^{\circ} \mathrm{C}$, and gelatinization temperatures of sweet potato starch are reported ranging between $58^{\circ} \mathrm{C}$ and $84^{\circ} \mathrm{C}$ [11], caused modifications or rupture of starch granular structure, and these fragments can combine with other molecules creating new compounds resistant to enzymatic digestion [8]. Previous research reported that steam cooking at atmospheric pressure formed higher RSC than steam cooked at higher pressure [12]. In addition, recrystallization during retrogradation could be formed by the association between amylose and amylopectin through the cooling of steamed rice bowl cake preparation [5], resulting in similar RSC between different varieties of sweet potatoes. Furthermore, processing raw materials in most food destroys RSI and RSII, but it can produce RSIII(retrograded starch) [12]. RSIII is produced by starch gelatinization, which is a disruption of granular structure by heating starch with excess water, and then retrogradation during cooling.

Compared with different varieties and proportion of sweet potatoes, the control (TCS 17) has the lowest RSC. Previous research [14] reported that various factors such as milling degree, heating operation, moisture content during cooking, and other components in food are known to affect the formation of RS III in processed foods. In addition, the higher RSC in processing food may attribute to the combination of starch and other molecules (proteins or lipids) which forms new compounds. Furthermore, the encapsulation of starch molecule by protein matrix in food [8], and the interaction between starch and amylose and/or amylopectin [15], increase the realignment of starch chains, leading to it less susceptible to enzymatic digestion and an also limit the action of amylolytic enzymes on substrate, further influencing RS III formation.

It was observed in Table 2 that TN 66 with higher proportion produced higher RSC (10.60, 11.18 and $12.01 \%)$, and was similar to the results of TN $57(10.31$, 10.70 and $11.16 \%)$ and TN 73 (10.50, 11.17 and $11.87 \%)$. The $30 \%$ proportion showed the highest RSC (12.01\%) in TN 66. The $10 \%$ proportion displayed lowest RSC $(10.31 \%)$ in TN 57 . Higher RSC could be observed in this research when compared with previous researches [16], and this may be attributed to the higher amylose content of TCS 17 and sweet potato [11], which retrogrades quickly during the first few hours of cooling after gelatinization of steamed rice bowl cake preparation.

Furthermore, TCS 17 has higher amylose content than Japonica rice. The high degree of amylose polymerization and the formation of amylolytic enzyme-resistant double helices stabilized by hydrogen bonds [17] and the moisture content about $30-60 \%$ during the preparation of steamed rice bowl cake may be attributed to the main reasons. It is known that water acts as a plasticizer for retrogradation and the retrogradation of starch can be maximized in about 30-60\% moisture content [18].

Table 2. The Resistant Starch Analysis Result of Steamed Rice Bowl Cake With Different Proportion of Sweet Potatoes

\begin{tabular}{|c|c|}
\hline Experiment variable & Resistant starch (\%) \\
\hline Control & $10.00^{\mathrm{h}}$ \\
\hline $10 \%$ & $10.31^{\mathrm{g}}$ \\
\hline TN $57 \quad 20 \%$ & $10.70^{\mathrm{d}}$ \\
\hline $30 \%$ & $11.16^{\mathrm{c}}$ \\
\hline $10 \%$ & $10.60^{\mathrm{e}}$ \\
\hline TN $66 \quad 20 \%$ & $11.18^{\mathrm{c}}$ \\
\hline $30 \%$ & $12.01^{\mathrm{a}}$ \\
\hline $10 \%$ & $10.50^{\mathrm{f}}$ \\
\hline TN $73 \quad 20 \%$ & $11.17^{\mathrm{c}}$ \\
\hline $30 \%$ & $11.87^{\mathrm{b}}$ \\
\hline
\end{tabular}

Different superscript letters indicate significant differences $(p<0.05)$. TN 57=Tainung No.57; TN 66=Tainung No. 66; TN 73=Tainung No. 73. 


\subsection{Texture Profile Analysis (TPA) of Steamed Rice Bowl Cake}

Texture is one of the major factors which influence food acceptability, especially for rice-made food. The texture profile analysis of steamed rice bowl cake based on different varieties of sweet potatoes (TN 57, TN 66 and TN 73) and proportion (0, 10, 20 and 30\%) was shown in Table 3. Significant differences $(p<0.05)$ were found in all experiment variables of texture profile analysis. Compared with other experiment variable, the $30 \%$ proportion showed the highest hardness, cohesiveness, adhesiveness, brittleness, springiness and chewiness. This result indicates that the higher proportion of the sweet potato, the better texture of the steamed rice bowl cake.

The texture properties of rice starch gel depend upon structure of starch granule and composition. The pattern may be explained by the amount of crude fiber present in the sweet potato which absorbs more water. This pattern especially was found in TN 66, this may be explained by higher crude fiber of TN 66. This result was also observed by Montes et al. [19], who observed that cookies containing tapioca and rice flour displayed higher hardness.

In this research, compared with the control, the higher hardness, cohesiveness, adhesiveness, brittleness, springiness and chewiness of steamed rice bowl cake was presumably attributed to its higher crude fibers content, and the greater extent of starch granule swelling was because of the lower protein and lipid content. Lee et al. [20] reported the hardness of a starch gel increased linearly with retrogradation time during storage and solid content of starch gel. Especially, the retrogradation rate is highly correlated with the starch content of gel. In a starch gel, maximum rate of retrogradation was observed at a $50-55 \%$ solid content [20], similar to the steamed rice bowl cake in this study, the starch retrogradation rate might continuously and quickly increase. In addition, rigidity of starch gel is highly correlated with retrogradation of starch granules, syneresis and crystallisation of amylopectin [21]. Though the starch molecules in starch-rich food is enhanced during retrogradation leading to an increase in the hardness of steamed rice bowl cake [22]. Therefore, presence of soluble carbohydrates from the sweet potato in blended rice with relatively high amylose content materials could enhance retrogradation of starch gel that would gave rise to harder gels. Puncha-arnon and Uttapap [23] indicated that the starch gel formation mainly depends on hold water in the network within the swollen starch granules. Amylose leaks out of the swollen starch granules also plays an important role, but it becomes significant when the swollen starch granules disrupt. Other components in starch gel, including protein, lipid, and non-starch polysaccharide, would also facilitate or impede the network formation within the swollen starch granules.

Hardness, cohesiveness, brittleness, springiness and chewiness of all steamed rice bowl cake were in the range of 249.9-307.0 gf, 434.1-532.0, 146.5-165.7 gf, 0.411-0.735 gf, 0.834-1.176 and 1.044-1.339 gf, respectively. This indicates that the steamed rice bowl cake with different varieties and proportion $(0,10,20$ and $30 \%$ ) of sweet potato (TN 57, TN 66 and TN 73) are with good acceptability. From these results, we concluded that the $30 \%$ proportion in TN 66 was the most suitable for making the steamed rice bowl cake.

\subsection{Color Evaluation of Steamed Rice Bowl Cake}

Color analysis results presented in Table 4 showed that color of steamed rice bowl cake with different varieties (TN 57, TN 66 and TN 73) and proportion (0, 10, 20 and $30 \%)$ of sweet potatoes were significantly different $(p<$ $0.05)$. The measured $L^{*}$ value of steamed rice bowl cake ranged between 25.97 and 67.99. Compared with different varieties and proportions of sweet potatoes, the control (TCS 17) was significantly lighter $\left(\mathrm{L}^{*}=67.99\right)$ than TN $57\left(\mathrm{~L} *=61.97,59.53\right.$ and 57.17), TN $66\left(\mathrm{~L}^{*}=51.25,49.58\right.$ and 47.41) and $\mathrm{TN} 73\left(\mathrm{~L}^{*}=36.89,31.33\right.$ and 25.97). This research revealed that $\mathrm{L}^{*}$ value decreased with increasing sweet potato proportion, which may be attributed to the deep color of the sweet potato. Previous research indicated some varieties of sweet potatoes were rich in different colored pigments, such as $\beta$-carotene, anthocyanin, and phenolic compounds, are responsible for different colors in sweet potatoes [24]. These different pigments were responsible for different colors in food.

Table 3. The Texture Profile Analysis (TPA) Result of Steamed Rice Bowl Cake With Different Sweet Potato Proportions

\begin{tabular}{|c|c|c|c|c|c|c|c|}
\hline $\begin{array}{c}\text { Experiment } \\
\text { variable }\end{array}$ & $\begin{array}{l}\text { Hardness } \\
\text { (gf) }\end{array}$ & Cohesiveness & $\begin{array}{c}\text { Adhesiveness } \\
\text { (gf.sec) }\end{array}$ & $\begin{array}{c}\text { Gumminess } \\
\text { (gf) }\end{array}$ & $\begin{array}{c}\text { Brittleness } \\
\text { (gf) }\end{array}$ & Springness & $\begin{array}{c}\text { Chewiness } \\
\text { (gf) }\end{array}$ \\
\hline Control & $283.3^{c}$ & $491.0^{c}$ & $-127.4^{\mathrm{c}}$ & $154.7^{\text {ef }}$ & $0.627^{\mathrm{c}}$ & $1.045^{\mathrm{b}}$ & $1.288^{\mathrm{b}}$ \\
\hline TN $57 \quad 20 \%$ & $260.0^{\mathrm{d}}$ & $458.0^{\mathrm{d}}$ & $-136.0^{\mathrm{d}}$ & $160.5^{\mathrm{d}}$ & $0.519^{\mathrm{e}}$ & $0.910^{\mathrm{c}}$ & $1.133^{\mathrm{d}}$ \\
\hline $30 \%$ & $283.2^{\mathrm{c}}$ & $490.0^{c}$ & $-127.1^{\mathrm{c}}$ & $154.0^{\mathrm{f}}$ & $0.622^{\mathrm{c}}$ & $1.040^{\mathrm{b}}$ & $1.281^{\mathrm{b}}$ \\
\hline TN $66 \quad 20 \%$ & $284.0^{\mathrm{c}}$ & $498.0^{\mathrm{c}}$ & $-127.5^{\mathrm{c}}$ & $154.0^{\mathrm{e}}$ & $0.632^{\mathrm{c}}$ & $1.055^{\mathrm{b}}$ & $1.289^{\mathrm{b}}$ \\
\hline $30 \%$ & $307.0^{\mathrm{a}}$ & $532.0^{\mathrm{a}}$ & $-114.1^{\mathrm{a}}$ & $145.5^{\mathrm{h}}$ & $0.735^{\mathrm{a}}$ & $1.176^{\mathrm{a}}$ & $1.339^{\mathrm{a}}$ \\
\hline $10 \%$ & $266.0^{\mathrm{d}}$ & $438.0^{\mathrm{e}}$ & $-141.6^{\mathrm{f}}$ & $161.9^{c}$ & $0.516^{\mathrm{e}}$ & $0.937^{\mathrm{c}}$ & $1.191^{\mathrm{c}}$ \\
\hline TN $73 \quad 20 \%$ & $284.0^{\mathrm{c}}$ & $495.0^{\mathrm{c}}$ & $-127.3^{c}$ & $157.2^{\mathrm{e}}$ & $0.631^{\mathrm{c}}$ & $1.052^{\mathrm{b}}$ & $1.285^{\mathrm{b}}$ \\
\hline $30 \%$ & $291.0^{\mathrm{b}}$ & $507.0^{\mathrm{b}}$ & $-116.4^{b}$ & $146.5^{\mathrm{g}}$ & $0.720^{\mathrm{b}}$ & $1.163^{\mathrm{a}}$ & $1.317^{\mathrm{a}}$ \\
\hline
\end{tabular}

Different superscript letters indicate significant differences $(p<0.05)$.

TN 57=Tainung No.57; TN 66=Tainung No. 66; TN 73=Tainung No. 73. 
The deep red color and yellow color of sweet potatoes were confirmed by their higher $a^{*}$ and $b^{*}$ values. Higher $\mathrm{a}^{*}$ and $\mathrm{b}^{*}$ values indicated yellow-orange color in steamed rice bowl cake with different varieties of sweet potatoes (TN 66, TN 73 and TN 57, TN 66) may due to the carotenoid pigments [25]. This may be possibly explained by the fact that TN 57, TN 66 and TN 73 were the variety of yellow, red and purple, respectively. Some researches $[26,27]$ reported that the yellow sweet potato (TN 57) contains higher amount of $\beta$-carotene, vitamin A $[28,29]$ and the red, purple sweet potato (TN 66 and TN 73) contains anthocyanin pigment, total phenolic [30]. Moreover, it has been reported that $\beta$-carotene is the precursor of Vitamin A [28], serves as an important nutritional component in foods as it has functional properties due to their antioxidative activity.

Table 4. The Color Analysis Results of Steamed Rice Bowl Cake With Different Sweet Potato Proportions

\begin{tabular}{cccr}
\hline Experiment variable & $\mathrm{L}^{*}$ & $\mathrm{a}^{*}$ & $\mathrm{~b}^{*}$ \\
\hline Control & $67.99^{\mathrm{a}}$ & $-2.24^{\mathrm{g}}$ & $0.44^{\mathrm{g}}$ \\
\hline $10 \%$ & $61.97^{\mathrm{b}}$ & $-3.32^{\mathrm{h}}$ & $7.91^{\mathrm{f}}$ \\
TN $5720 \%$ & $59.53^{\mathrm{c}}$ & $-3.53^{\mathrm{i}}$ & $11.96^{\mathrm{e}}$ \\
$30 \%$ & $57.17^{\mathrm{d}}$ & $-3.77^{\mathrm{j}}$ & $16.09^{\mathrm{d}}$ \\
\hline $10 \%$ & $51.25^{\mathrm{e}}$ & $1.01^{\mathrm{f}}$ & $22.78^{\mathrm{c}}$ \\
TN $6620 \%$ & $49.58^{\mathrm{f}}$ & $2.87^{\mathrm{e}}$ & $30.38^{\mathrm{b}}$ \\
$30 \%$ & $47.41^{\mathrm{g}}$ & $4.67^{\mathrm{d}}$ & $38.11^{\mathrm{a}}$ \\
\hline $10 \%$ & $36.89^{\mathrm{h}}$ & $9.79^{\mathrm{C}}$ & $-9.61^{\mathrm{g}}$ \\
TN $7320 \%$ & $31.33^{\mathrm{i}}$ & $13.33^{\mathrm{b}}$ & $-11.86^{\mathrm{i}}$ \\
$30 \%$ & $25.97^{\mathrm{j}}$ & $16.99^{\mathrm{a}}$ & $-14.26^{\mathrm{j}}$ \\
\hline
\end{tabular}

Different superscript letters indicate significant differences $(p<0.05)$.

TN 57=Tainung No.57; TN 66=Tainung No. 66; TN 73=Tainung No. 73.

\section{Conclusion}

Results of this research revealed the effects of different varieties (TN 57, TN 66 and TN 73) and proportion $(0,10$, 20 and $30 \%$ ) of sweet potatoes on the RSC, texture profile analysis and color of steamed rice bowl cake. According to the results, the RSC and color were significantly affected by different varieties and proportion of sweet potatoes. The effects of different varieties and proportion of sweet potatoes on RSC of steamed rice bowl cake showed that TCS 17 had the lowest RSC. Some similar RSC among different varieties of sweet potatoes was observed. The above results suggest that firms should consider this method to further develop the Taiwanese traditional rice-made food with high RSC.

Moreover, significant differences $(p<0.05)$ were found in all experiment variables of texture profile analysis. Compared with other experiment variables, the $30 \%$ proportion of the sweet potato showed the highest hardness, cohesiveness, adhesiveness, brittleness, springiness and chewiness. That is to say, the hardness, cohesiveness, adhesiveness, brittleness, springiness and chewiness of steamed rice bowl cake were positively related to the proportion of sweet potato. Furthermore, the color analysis results of steamed rice bowl cake were significantly affected by the different flesh colors of sweet potato varieties and proportion. Higher $\mathrm{a}^{*}$ and $\mathrm{b}^{*}$ values indicate that yellow-orange color in steamed rice bowl can be attributed to different varieties of sweet potatoes. Thus, this suggests that the food industry should consider the application of different varieties of sweet potatoes in order to further develop rice-made food. In summary, results of this research suggest that the sweet potato is not only a potentially useful but also a natural material for high RSC in the manufacturing of rice-made food.

\section{Acknowledgments}

We thank the Meiho University in Pingtung supporting excellent equipments and technology. All of the authors participated in this study, and read and approved the final manuscript.

\section{References}

[1] Chou, C.F., Yen, T.F., and Li, C.T., "Effects of different cooking methods and particle size on resistant starch content and degree of gelatinization of a high amylose rice cultivar in Taiwan," Journal of Food, Agriculture and Environment, 12 (2). 6-10. 2014.

[2] Wang, L., Xie, B., Shi, J., Xue, S., Deng, Q., Wei, Y., and Tian, B., "Physicochemical properties and structure of starches from Chinese rice cultivars," Food Hydrocolloids, 24(2). 208-216. 2010.

[3] Shamai, K., Bianco-Peled, H., and Shimoni, E., "Polymorphism of resistant starch type III," Carbohydrate Polymers, 54. 363-369. 2003.

[4] Goni, I., Garcia-Diz, L., Manas, E., and Saura-Calixto, F., "Analysis of resistant starch: A method for foods and food products," Food Chemistry, 56(4). 445-449. 1996.

[5] Mun, S., and Shin, M., "Mild hydrolysis of resistant starch from maize," Food Chemistry, 96(1). 115-121. 2006.

[6] Zhang, W., Bi, J., Yan, X., Wang, H., Zhu, C., Wang, J., and Wan, J., "In vitro measurement of resistant starch of cooked milled rice and physico-chemical characteristics affecting its formation," Food Chemistry, 105(2). 462-468. 2007.

[7] Alderson, A. K., and Guraya, H. S., "Effects of microwave heat moisture treatment on properties of waxy and non-waxy rice starches," Food Chemistry, 97(2). 318-323. 2006.

[8] Walter, M., Silva, P., and Denardin, C., "Rice and resistant starch: Different content depending on chosen methodology," Journal of Food Composition and Analysis, 18(4). 279-285. 2005.

[9] Namratha, J., Asna, U., and Prasad, N., "Effects of storage on resistant starch content of processed ready-to-eat foods," Food Chemistry, 79(3). 395-400. 2002.

[10] Odenigbo, A., Rahimi, J., Ngadi, M., Amer, S., and Mustafa, A., "Starch digestibility and predicted glycemic index of fried sweet potato cultivars," Functional Foods in Health and Disease, 2(7). 280-289. 2012.

[11] Jha, A. K., and Bhattacharya, A., "Preparation and in vito evaluation of sweet potato starch blended sodium alginate microbeads," Advances in Natural and Applied Sciences, 2(3). 122-129. 2008.

[12] Abioye, V. F., Adeyemi, I. A., Akinwande, B. A., Kulakow, P., and Maziya-Dixon, B., "Effect of steam cooking and storage time on the formation of resistant starch and functional properties of cassava starch," Cogent Food and Agriculture, 3, 1-11. 2017.

[13] Garcia-Alonso A., Jimenez-Escrig A., Martin-Carron N., Bravo L., and Sauro-Calixto F., "Assessment of some parameters involved in the gelatinization and retrogradation of starch," Food Chemistry, 66(2). 181-187. 1999

[14] Kumari, M., Urooj, A., and Prasad, N., "Effect of storage on resistant starch and amylose content of cereal-pulse based readyto-eat commercial products," Food Chemistry, 102(4). 1425-1430. 2006.

[15] Wu, Y., Chen, Z., Li, X., and Wang, Z., "Retrogradation properties of high amylose rice flour and rice starch by physical modification," LWT-Food Science and Technology, 43(3). 492-497. 2010.

[16] Sagum, R., and Arcot, J., "Effect of domestic processing methods on the starch, non-starch polysaccharides and in vitro starch and protein digestibility of three varieties of rice with varying levels of amylose," Food Chemistry, 70(1). 107-111. 2000. 
[17] Abdel-Aal, E.M., and Rabalski, I., "Effect of baking on nutritional properties of starch in organic spelt whole grain products," Food Chemistry, 111. 150-156. 2008.

[18] Lin, J., Wang, S., and Chang, Y., "Effects of molecular size on gelatinization thermal properties before and after annealing of rice starch with different amylose contents," Food Hydrocolloids, 22(1). 156-163. 2008.

[19] Montes, S.D.S., Rodrigues, L.M., Cardoso, R.D.C.V., Camilloto, G.P., and Cruz, R.S., "Tapioca and rice flour cookies: technological, nutritional and sensory properties," Ciência $e$ Agrotecnologia, 39(5), 514-522. 2015.

[20] Lee, S.Y., Woo, K.S., Lim, J.K., Kim, H.I., and Lim, S.T., "Effect of processing variables on texture of sweet potato starch noodles prepared in a nonfreezing process," Cereal chemistry, 82(4). 475478. 2005.

[21] Ng, K.R., Abbas, R.M.A., Tan, T.C., and Azhar, M.E., "Physicochemical, pasting and gel textural properties of wheatripe Cavendish banana composite flours," International Food Research Journal, 21(2). 655-662. 2014.

[22] Charoenrein, S., and Preechathammawong, N., "Effect of waxy rice flour and cassava starch on freeze-thaw stability of rice starch gels," Carbohydrate Polymers, 90. 1032-1037. 2012.

[23] Puncha-arnon, S., and Uttapap, D., "Rice starch vs. rice flour: Differences in their properties when modified by heat-moisture treatment," Carbohydrate polymers, 91(1). 85-91. 2013.

[24] Sanoussi, A.F., Dansi, A., Ahissou, H., Adebowale, A., Sanni, L. O., Orobiyi, A., and Sanni, A., "Possibilities of sweet potato [Ipomoea batatas $(\mathrm{L}.) \mathrm{Lam}$ ] value chain upgrading as revealed by physico-chemical composition of ten elites landraces of Benin," African Journal of Biotechnology, 15(13). 481-489. 2016.

[25] Adepoju, A.L., and Adejumo, B.A., "Some Proximate Properties Of Sweet Potato (Ipomoea Batatas L) As Influenced By Cooking Methods," International Journal of Scientific \& Technology Research, 4(3). 146-148. 2015.

[26] Rose, I.M., and Vasanthakaalam, H., "Comparison of the nutrient composition of four sweet potato varieties cultivated in Rwanda," American journal of food and nutrition, 1(1). 34-38. 2011.

[27] Etudaiye, H.A., Oti, E., Aniedu, C., and Omodamiro, M.R., "Utilization of sweet potato starches and flours as composites with wheat flours in the preparation of confectioneries," African Journal of Biotechnology, 14(1). 17-22. 2015.

[28] Omodamiro, R.M., Afuape, S.O., Njokwu, C.J., Nwankwo, II.M., Echendu, T.N.C., and Carey, T., "Acceptability and proximate composition of some sweet potato genotypes: implication of breeding for food security and industrial quality," International Journal of Biotechnology and Food Science, 1(5). 97-101. 2013.

[29] Rodrigues, N.R., Junior, J.B., and Barbosa, M.I.M.J., "Determination of physico-chemical composition, nutritional facts and technological quality of organic orange and purple-fleshed sweet potatoes and its flours," International Food Research Journal, 23(5). 2071-2078. 2016.

[30] Malomo, O., Jimoh, M.O., Adekoyeni, O.O., Soyebi, O.E., and Alamu, E.A., "Effect of blanching and unblanching on rheological properties of sweet-potato bread," Academic research international, 4(3). 24-47. 2013. 